\title{
Identification of new superwarfarin-type rodenticides by structural similarity. The docking of ligands on the vitamin $K$ epoxide reductase enzyme's active site
}

\author{
László FERENCZ, ${ }^{*}$ Daniela Lucia MUNTEAN ${ }^{2}$ \\ ${ }^{1}$ Sapientia Hungarian University of Transylvania, \\ Faculty of Technical and Human Sciences, \\ Str. Sighişoarei 1C, Târgu-Mureş - Corunca, 540485, Romania, \\ e-mail: lferencz@inbox.com ("corresponding author) \\ ${ }^{2}$ University of Medicine and Pharmacy Târgu-Mureș, Faculty of Pharmacy, \\ Str. Gh. Marinescu 38, Târgu-Mureș, 540139, Romania
}

Manuscript received June 5, 2015; revised August 20, 2015; accepted August 30, 2015

\begin{abstract}
The rodenticide brodifacoum is highly toxic to mammals and birds, and extremely toxic to fish. It is a highly cumulative poison due to its high lipophilicity and extremely slow elimination. For this reason, it may be interesting to find similar compounds in order to enlarge the spectrum of vitamin $\mathrm{K}$ epoxide reductase enzyme inhibitors used today in pest control. We used the Similar Compounds search type of the Chemical Structure Search of the PubChem Compound Database to locate records that are similar to the chemical structure of brodifacoum, using pre-specified similarity thresholds. Using the threshold $\geq$ than $95 \%$ for the similar structures criteria, we found 14 compounds (from over 30 million entries) that meet this criteria. Two of these compounds have a better binding affinity to vitamin $\mathrm{K}$ epoxide reductase enzyme than brodifacoum, but the binding energy of the other 12 substances is also high, having identical or lower lipophilicity; consequently, they will eliminate faster, possibly lacking a part of the adverse effects.
\end{abstract}

Keywords: brodifacoum, structural similarity, screening, docking

\section{Introduction}

Brodifacoum (PubChem Compound Identifier, $\mathrm{CID}=54680676$ ) is a coumarin-derived rodenticide. It was first introduced in 1975 to deal with the public health problem of warfarin-resistant rodents. 
Brodifacoum is a weak acid which does not readily form water soluble salts. It does not lose activity after 30 days in direct sunlight. This rodenticide is effective against warfarin-resistant rats. Currently, it is registered for the control of rats and mice in and around farm structures, households, and domestic dwellings, inside transport vehicles, commercial transportation facilities, industrial areas, sewage systems, aircraft, ships, boats, railway cars, and food processing, handling, and storage areas. Products containing brodifacoum are available to the general public and application may be made as often as necessary. Brodifacoum is formulated as meal bait, paraffinized pellets, rat and mouse bait ready-to-use place packs, and paraffin blocks. All end-use products contain 0.005 percent active ingredient. [1]

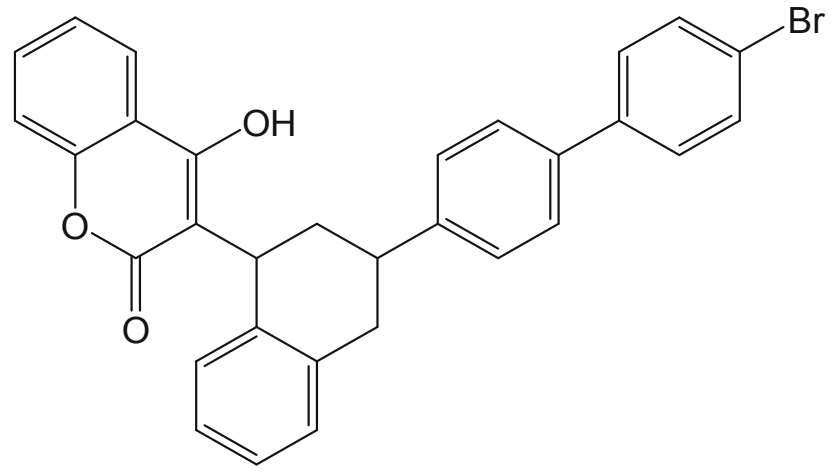

54680676

Brodifacoum was made a "restricted-use" pesticide in 2008 by EPA, meaning it can only be used by certified pesticide applicators. The product remains on the market for public use.

Brodifacoum is absorbed through the gut and works by preventing the normal clotting of blood, leading to fatal hemorrhage [1]. It inhibits coagulation by antagonizing the action of vitamin $\mathrm{K}$. Warfarin prevents the recycling of vitamin $\mathrm{K}$ by blocking vitamin $\mathrm{K}$ epoxide reductase (VKOR) activity, thus creating a functional vitamin $\mathrm{K}$ deficiency. Inadequate gamma-carboxylation of vitamin $\mathrm{K}$ dependent coagulation proteins interferes with the coagulation cascade, which inhibits blood clot formation. [2]

Death usually occurs through gastric hemorrhage. It is retained in the tissues at high rates, sometimes remaining in organ systems during the entire lifetime of an exposed animal. In a study that measured the retention of radioactive brodifacoum in the livers of single-dosed rats, $34 \%$ of the single dose is found in the liver after 13 weeks, and $11 \%$ of the dose remained in the liver for 104 weeks, approaching the normal lifespan of a rat. [1] 
It is highly effective in small doses - usually a rodent ingests a fatal dose after a single feeding and will die within 4-5 days. The greatest risk to wildlife from brodifacoum is secondary poisoning. Rodents continue to eat poisoned bait, so at the time of death the amount of brodifacoum present in their bodies is many times the amount required to kill them. Non-target wildlife, such as predators and scavengers, may then consume rodents that have ingested large doses of brodifacoum [1]. It can take as little as one poisoned rodent, or a predator may accumulate enough brodifacoum after consuming several poisoned prey items, to induce life-threatening or fatal effects. A single dose of brodifacoum can depress blood clotting for months in some animals, including birds. Stress or slight wounds incurred in the field, such as small scratches that normally occur when a raptorial bird captures its prey, are often sufficient to cause a fatal hemorrhage [1].

It is very highly toxic to aquatic organisms, mammals and birds. Due to its extremely low solubility and usage patterns, however, it is assumed that not enough brodifacoum would dissolve in water to create a hazard to aquatic non-target animals. Products used in sewers are water-resistant paraffinized blocks and are not expected to dissolve in water. But hundreds of avian and other wildlife mortalities have been reported across North America [3].

Because of this, it may be interesting to find similar compounds in order to enlarge the spectrum of VKOR inhibitors used today in pest control. We used the Similar Compounds search type of the Chemical Structure Search of the PubChem Compound Database [7] to locate records that are similar to the chemical structure of brodifacoum, using pre-specified similarity thresholds. Using the threshold $\geq$ than $95 \%$ for the similar structures criteria, we found 14 compounds that meet this criteria. In accordance with our calculations and molecular docking simulations, two of these compounds have a better binding affinity to vitamin $\mathrm{K}$ epoxide reductase enzyme than brodifacoum, but the binding energy of the other 12 substances is also high, having identical or lower lipophilicity; consequently, they will eliminate faster, possibly lacking a part of the adverse effects.

\section{Materials and methods}

Hardware: Asus X401A PC, CPU Dual Core Intel 820, 1.7GHz, 4 GB RAM.

Software: OS Windows 7 - 64 bit, Chem 3D Ultra 10.0, ChemDraw Pro 10.0, AutoDock Tools 1.5.6 Molecular Graphics Laboratory The Scripps Research Institute [4], AutoDock Vina by Sargis Dallakyan, The Scripps Research Institute [5], Open Babel 2.3.2. [6], PyRx 0.8, PubChem Compound Database, Firefox 28.0. 
The Similar Compounds search type of the Chemical Structure Search of the PubChem Compound Database [7] allows to locate records that are similar to a chemical structure query using pre-specified similarity thresholds. Similarity is measured using the Tanimoto equation and the PubChem dictionary-based binary fingerprint. This fingerprint consists of series of chemical substructure "keys". Each key denotes the presence or absence of a particular substructure in a molecule. The fingerprint does not consider variation in stereochemical or isotopic information. Collectively, these binary keys provide a "fingerprint" of a particular chemical structure valence-bond form.

The degree of similarity is dictated by the Threshold parameter. A threshold of " $100 \%$ " effectively acts as an "exact match" to the provided chemical structure query (ignoring stereo or isotopic information), while a threshold of " $0 \%$ " would return all chemical structures in the PubChem Compound database. Various predefined thresholds between $99 \%$ and $60 \%$ are allowed [7].

Searching the databases (with over 30 million entries) is possible for a broad range of properties including chemical structure, name fragments, chemical formula, molecular weight, $\mathrm{X} \log \mathrm{P}$, and hydrogen bond donor and acceptor count. PubChem can be accessed for free through a web user interface.

AutoDock Vina [5] significantly improves the average accuracy of the binding mode predictions compared to AutoDock 4. For its input and output, Vina uses the same PDBQT molecular structure file format used by AutoDock. PDBQT files can be generated (interactively or in batch mode) and viewed using MGLTools. Other files, such as the AutoDock and AutoGrid parameter files (GPF, DPF) and grid map files, are not needed. The docking calculation consists of a number of independent runs, starting from random conformations. Each of these runs consists of a number of sequential steps. Each step involves a random perturbation of the conformation followed by a local optimization (using the Broyden-Fletcher-Goldfarb-Shanno algorithm) and a selection in which the step is either accepted or not. Each local optimization involves many evaluations of the scoring function as well as its derivatives in the position-orientation-torsions coordinates. The number of evaluations in a local optimization is guided by convergence and other criteria. The number of steps in a run is determined heuristically, depending on the size and flexibility of the ligand and the flexible side chains. However, the number of runs is set by the exhaustiveness parameter. Since the individual runs are executed in parallel, where appropriate, exhaustiveness also limits the parallelism. Unlike in AutoDock 4, in AutoDock Vina, each run can produce several results: promising intermediate results are remembered. These are merged, refined, clustered, and sorted automatically to produce the final result $[8,9,10,11$, and 12$]$. 
Vina creates *_out.pdbqt files, where it stores all docked poses and scores [5].

The predicted binding affinity of bound structures is given in $\mathrm{kcal} / \mathrm{mol}$. To compare the accuracy of the predictions of the experimental structure, AutoDock Vina uses a measure of distance between the experimental and predicted structures, RMSD: root-mean-square deviation.

RMSD values are calculated relative to the best mode and using only movable heavy atoms. For scoring, AutoDock Vina uses a united-atom function, which involves only the heavy atoms $[4,5$, and 8$]$.

Two variants of RMSD metrics are provided by the software, rmsd/lb (RMSD lower bound) and rmsd/ub (RMSD upper bound), differing in how the atoms are matched in the distance calculation [5]:

- $\quad r m s d / u b$ matches each atom in one conformation with itself in the other conformation, ignoring any symmetry;

- $\quad r m s d^{\prime}$ matches each atom in one conformation with the closest atom of the same element type in the other conformation (rmsd' can not be used directly because it is not symmetric);

- $r m s d / l b$ is defined as follows: $\mathrm{rmsd} / \mathrm{lb}\left(\mathrm{c}_{1}, \mathrm{c}_{2}\right)=\max \left(\left(\operatorname{rmsd}^{\prime}\left(\mathrm{c}_{1}, \mathrm{c}_{2}\right)\right.\right.$, $\left.\operatorname{rmsd}^{\prime}\left(\mathrm{c}_{2}, \mathrm{c}_{1}\right)\right)$.

\section{Results and discussions}

Using the Chemical Structure Search of the PubChem Compound Database [7] and a threshold $\geq$ than $95 \%$ for the similar structures criteria, we detected 14 compounds $95 \%$ similar with brodifacoum. We calculated the binding affinities for the ligands (including for brodifacoum) to the surface of the VKOR enzyme. Fourteen substances (with PubChem Compound ID $=54721414,54721409$, 54721416, 54702967, 54702968, 56999900, 54676115, 54716798, 56610083, $56638536,56629283,57166454,57186316,54736729)$ are excellent ligands for VKOR. These ligands are shown in Table 1 and below, together with brodifacoum (CID 54680676).

Table 1. The 14 ligands with a similarity threshold $\geq 95 \%$, and brodifacoum (54680676)

\begin{tabular}{ccccc}
\hline $\begin{array}{c}\text { PubChem } \\
\text { CID [7] }\end{array}$ & IUPAC Name & $\begin{array}{c}\text { Molecular } \\
\text { Formula }\end{array}$ & $\begin{array}{c}\text { MW } \\
\text { [g/mol] }\end{array}$ & XlogP3 \\
\hline 54721414 & $\begin{array}{l}\text { 3-[3-[4-[[4-(4-bromophenyl)phenyl]methoxy] } \\
\text { phenyl]-1,2,3,4-tetrahydronaphthalen-1-yl]-4- } \\
\text { hydroxychromen-2-one }\end{array}$ & $\mathrm{C}_{38} \mathrm{H}_{29} \mathrm{BrO}_{4}$ & & \\
& & & \\
& & &
\end{tabular}




\begin{tabular}{|c|c|c|c|c|}
\hline $\begin{array}{l}\text { PubChem } \\
\text { CID [7] }\end{array}$ & IUPAC Name & $\begin{array}{l}\text { Molecular } \\
\text { Formula }\end{array}$ & $\begin{array}{c}\text { MW } \\
{[\mathrm{g} / \mathrm{mol}]}\end{array}$ & $\mathrm{X} \log \mathrm{P} 3$ \\
\hline 54721409 & $\begin{array}{l}\text { 3-[3-[4-[4-[(4-bromophenyl)methoxy]phenyl] } \\
\text { phenyl]-1,2,3,4-tetrahydronaphthalen-1-yl]-4- } \\
\text { hydroxychromen-2-one }\end{array}$ & $\mathrm{C}_{38} \mathrm{H}_{29} \mathrm{BrO}_{4}$ & 629.53846 & 9.1 \\
\hline 54680676 & $\begin{array}{l}\text { 3-[3-[4-(4-bromophenyl)phenyl]-1,2,3,4- } \\
\text { tetrahydronaphthalen-1-yl]-4-hydroxychromen } \\
\text {-2-one }\end{array}$ & $\mathrm{C}_{31} \mathrm{H}_{23} \mathrm{BrO}_{3}$ & 523.41652 & 7.6 \\
\hline 54721416 & $\begin{array}{l}\text { 3-[3-[4-[[4-(4-bromophenyl) phenyl]methyl] } \\
\text { phenyl]-1,2,3,4-tetrahydronaphthalen-1-yl]-4- } \\
\text { hydroxychromen-2-one }\end{array}$ & $\mathrm{C}_{38} \mathrm{H}_{29} \mathrm{BrO}_{3}$ & 613.53906 & 9.6 \\
\hline 54702967 & $\begin{array}{l}\text { 3-[3-[4-[2-(4-bromophenyl)ethyl]phenyl]- } \\
\text { 1,2,3,4-tetrahydronaphthalen-1-yl]-4- } \\
\text { hydroxychromen-2-one }\end{array}$ & $\mathrm{C}_{33} \mathrm{H}_{27} \mathrm{BrO}_{3}$ & 551.46968 & 8.2 \\
\hline 54702968 & $\begin{array}{l}\text { 3-[3-[4-[(4-bromophenyl)methoxy]phenyl]- } \\
\text { 1,2,3,4-tetrahydronaphthalen-1-yl]-4- } \\
\text { hydroxychromen-2-one }\end{array}$ & $\mathrm{C}_{32} \mathrm{H}_{25} \mathrm{BrO}_{4}$ & 553.4425 & 7.5 \\
\hline 56999900 & $\begin{array}{l}\text { 3-[[4-(4-bromophenyl)phenyl]- } \\
\text { cyclohexylmethyl]-4-hydroxychromen-2-one }\end{array}$ & $\mathrm{C}_{28} \mathrm{H}_{25} \mathrm{BrO}_{3}$ & 489.4003 & 7.6 \\
\hline 54676115 & $\begin{array}{l}\text { 3-[(1S,3R)-3-[4-(4-bromophenyl)phenyl]- } \\
\text { 1,2,3,4-tetrahydronaphthalen-1-yl]-4- } \\
\text { hydroxychromen-2-one }\end{array}$ & $\mathrm{C}_{31} \mathrm{H}_{23} \mathrm{BrO}_{3}$ & 523.41652 & 7.6 \\
\hline 54716798 & $\begin{array}{l}\text { 3-[(1R,3R)-3-[4-(4-bromophenyl)phenyl]- } \\
\text { 1,2,3,4-tetrahydronaphthalen-1-yl]-4- } \\
\text { hydroxychromen-2-one }\end{array}$ & $\mathrm{C}_{31} \mathrm{H}_{23} \mathrm{BrO}_{3}$ & 523.41652 & 7.6 \\
\hline 56610083 & $\begin{array}{l}\text { 3-[(2S,4R)-4-[4-(4-bromophenyl)phenyl]- } \\
\text { 1,2,3,4-tetrahydronaphthalen-2-yl]-4- } \\
\text { hydroxychromen-2-one }\end{array}$ & $\mathrm{C}_{31} \mathrm{H}_{23} \mathrm{BrO}_{3}$ & 523.41652 & 7.6 \\
\hline 56638536 & $\begin{array}{l}\text { 3-[(2R)-4-[4-(4-bromophenyl)phenyl]-1,2,3,4- } \\
\text { tetrahydronaphthalen-2-yl]-4- } \\
\text { hydroxychromen-2-one }\end{array}$ & $\mathrm{C}_{31} \mathrm{H}_{23} \mathrm{BrO}_{3}$ & 523.41652 & 7.6 \\
\hline 56629283 & $\begin{array}{l}3 \text {-[(2S)-4-[4-(4-bromophenyl)phenyl]-1,2,3,4- } \\
\text { tetrahydronaphthalen-2-yl]-4- } \\
\text { hydroxychromen-2-one }\end{array}$ & $\mathrm{C}_{31} \mathrm{H}_{23} \mathrm{BrO}_{3}$ & 523.41652 & 7.6 \\
\hline 57166454 & $\begin{array}{l}\text { 3-[1-[4-(4-bromophenyl)phenyl]-2- } \\
\text { phenylethyl]-4-hydroxychromen-2-one }\end{array}$ & $\mathrm{C}_{29} \mathrm{H}_{21} \mathrm{BrO}_{3}$ & 497.37924 & 6.8 \\
\hline 57186316 & $\begin{array}{l}3 \text {-[(2S)-1-[4-(4-bromophenyl)phenyl]-1,2,3,4- } \\
\text { tetrahydronaphthalen-2-yl]-4- } \\
\text { hydroxychromen-2-one }\end{array}$ & $\mathrm{C}_{31} \mathrm{H}_{23} \mathrm{BrO}_{3}$ & 523.41652 & 7.6 \\
\hline 54736729 & $\begin{array}{l}\text { 3-[(2R,4R)-4-[4-(4-bromophenyl)phenyl]- } \\
\text { 1,2,3,4-tetrahydronaphthalen-2-yl]-4- } \\
\text { hydroxychromen-2-one }\end{array}$ & $\mathrm{C}_{31} \mathrm{H}_{23} \mathrm{BrO}_{3}$ & 523.41652 & 7.6 \\
\hline
\end{tabular}




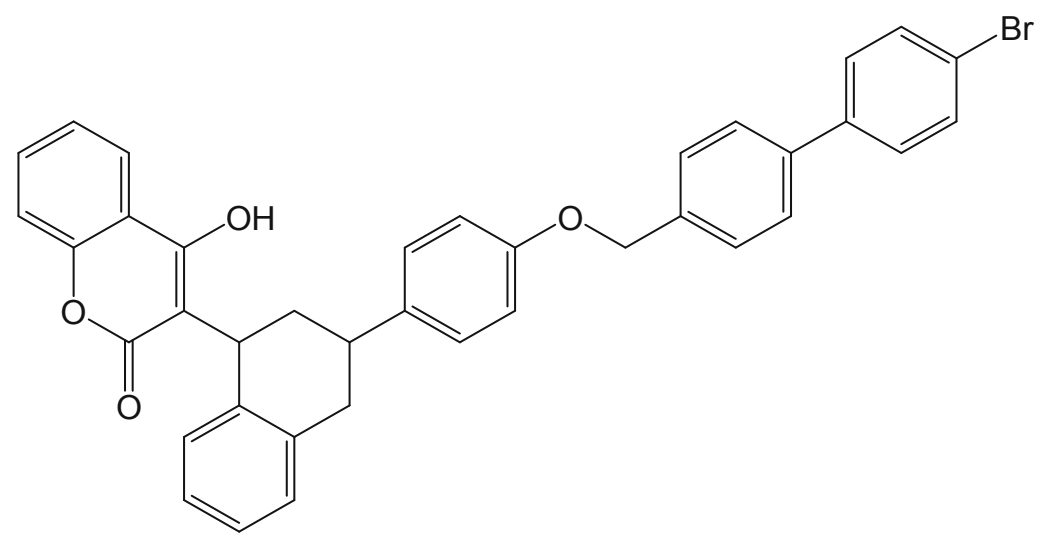

54721414

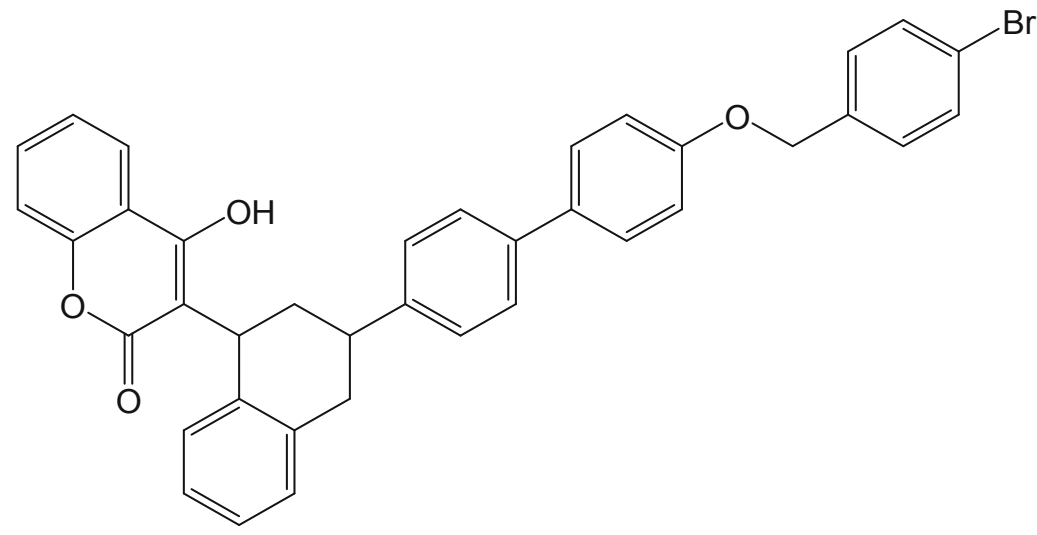

54721409

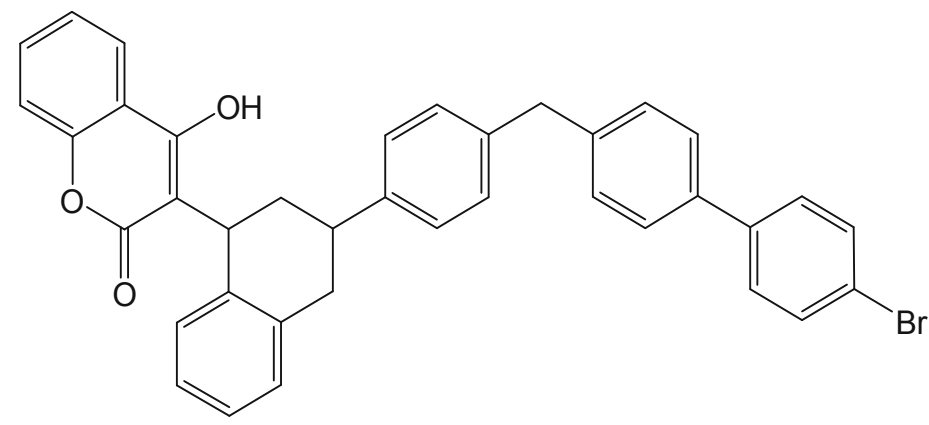

54721416 
<smiles>O=c1oc2ccccc2c(O)c1C1CC(c2ccc(CCc3ccc(Br)cc3)cc2)Cc2ccccc21</smiles>

54702967<smiles>O=c1oc2ccccc2c(O)c1C1CC(c2ccc(OCc3ccc(Br)cc3)cc2)Cc2ccccc21</smiles>

54702968<smiles>O=c1oc2ccccc2c(O)c1C(c1ccc(-c2ccc(Br)cc2)cc1)C1CCCCC1</smiles> 
<smiles>O=c1oc2ccccc2c(O)c1[C@H]1C[C@H](c2ccc(-c3ccc(Br)cc3)cc2)Cc2ccccc21</smiles>

54676115<smiles>O=c1oc2ccccc2c(O)c1[C@H]1C[C@@H](c2ccc(-c3ccc(Br)cc3)cc2)Cc2ccccc21</smiles>

54716798<smiles>O=c1oc2ccccc2c(O)c1[C@H]1Cc2ccccc2[C@H](c2ccc(-c3ccc(Br)cc3)cc2)C1</smiles>

56610083 
<smiles>O=c1oc2ccccc2c(O)c1[C@H]1Cc2ccccc2C(c2ccc(-c3ccc(Br)cc3)cc2)C1</smiles>

56638536<smiles>[R6][R6]([R6])([H])c1ccc2c(c1)C[C@@H](c1c(O)c3ccccc3oc1=O)C[C@H]2c1ccc(-c2ccc(Br)cc2)cc1</smiles><smiles>O=c1oc2ccccc2c(O)c1[C@H](Cc1ccccc1)c1ccc(-c2ccc(Br)cc2)cc1</smiles>

57166454 


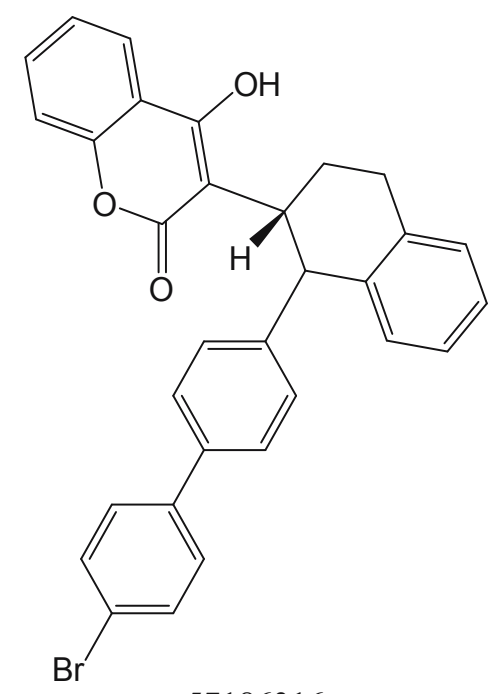

57186316

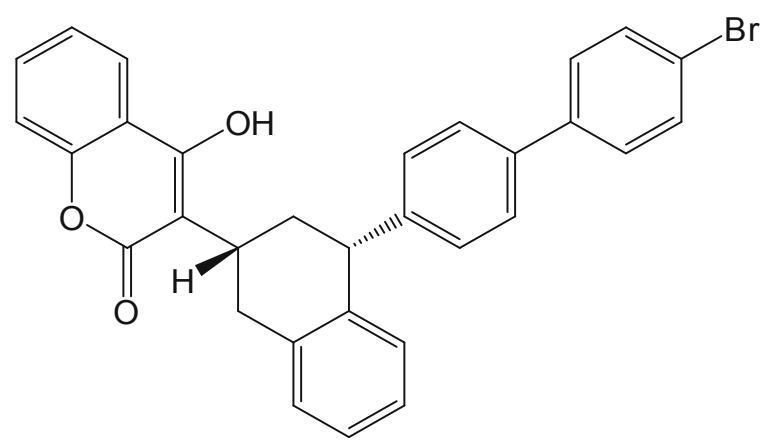

54736729

In Table 2, there are presented the calculated binding affinities in descending order for the ligands and the enzyme VKOR (PDB code 3KP9 [13]).

When using a flexible docking engine, then minimizing the input conformation of the ligands can reduce problems that are known to occur in conformer generation inside the docking engine, which arise if the input 3D conformation is not relaxed into good bond lengths and angles. For small molecules, a good choice is to use some of the molecular mechanics to optimize the structure down to a local energy minima like UFF or mm2. The assignment of 
Universal Force Field (UFF) atom types and the calculation of the molecular connectivity (identifying bonds, angular, torsional and inversion terms) has been performed using the routines available in the Open Babel package $[5,6]$. Open Babel can be used for refining initial geometries with UFF molecular-mechanics optimizations, adding or removing hydrogens to PDB protein files, and many other utility tasks that often arise in molecular modelling projects.

Open Babel supports a number of force fields which can be used for energy evaluation as well as energy minimization. We used the following energy minimization parameters: Conjugate Gradients optimization algorithm, 200 total number of steps; stop if energy difference is less than $0.1 \mathrm{kcal} / \mathrm{mol}$.

The virtual screening results show that the 14 compounds (Table 2) are strong inhibitors of VKOR. The structure of enzyme was retrieved with Chem 3D's Online Find Structure from the PDB ID option. The water molecules, other small molecules, such as solvent molecules and other relics of the isolation and crystallization procedures, were removed.

X-ray crystallography usually does not locate hydrogens, hence most PDB files do not include them. But hydrogens, particularly those that can form hydrogen bonds, are important in binding ligands; so, hydrogens were added to backbone $\mathrm{N}$ and to amine and hydroxyl side chains. Atoms were renumbered, and PDBQT files were generated with AutoDock Tools 1.5.6.

Table 2. The calculated binding affinities (including brodifacoum, $\mathrm{CID}=54680676$ ) in descending order for the enzyme VKOR (3KP9).

\begin{tabular}{|c|c|c|c|}
\hline Enzyme-Ligand & $\begin{array}{c}\text { Binding affinity } \\
{[\mathrm{kcal} / \mathrm{mol}]}\end{array}$ & $\begin{array}{c}\mathbf{r m s d} / \mathbf{u b} \\
{[\AA]}\end{array}$ & $\begin{array}{c}\mathbf{r m s d} / \mathbf{l b} \\
{[\AA]}\end{array}$ \\
\hline 3KP9 54721414_mmff94_E=259.03 & -11.3 & 0 & 0 \\
\hline 3KP9 54721409_mmff94_E $=203.54$ & -10.6 & 0 & 0 \\
\hline 3KP9_54680676_mmff94_E $=162.68$ & -10 & 0 & 0 \\
\hline 3KP9_54721416_mmff94_E $=182.96$ & -9.8 & 0 & 0 \\
\hline 3KP9_54702967_mmff94_E $=172.60$ & -9.5 & 0 & 0 \\
\hline 3KP9_54702968_mmff94_E $=173.00$ & -9.5 & 0 & 0 \\
\hline 3KP9_54721416_mmff94_E $=182.96$ & -9.5 & 2.003 & 1.139 \\
\hline 3KP9_54716798_mmff94_E $=880.70$ & -9.3 & 0 & 0 \\
\hline 3KP9_56999900_mmff94_E $=1010.91$ & -9.3 & 0 & 0 \\
\hline 3KP9 $54676115 \mathrm{mmff} 94 \mathrm{E}=880.70$ & -9.2 & 0 & 0 \\
\hline 3KP9_56610083_mmff94_E $=954.18$ & -9 & 0 & 0 \\
\hline 3KP9_56638536_mmff94_E $=956.00$ & -9 & 0 & 0 \\
\hline 3KP9 56629283 mmff94 E $=881.16$ & -8.7 & 0 & 0 \\
\hline 3KP9_57166454_mmff94_E $=125.89$ & -8.7 & 0 & 0 \\
\hline 3KP9_57186316_mmff94_E $=884.05$ & -8.7 & 0 & 0 \\
\hline 3KP9 54736729_mmff94_E $=903.33$ & -8.1 & 0 & 0 \\
\hline
\end{tabular}


The RMSD cut-off of $2 \AA$ is usually used as a criterion of the correct bound structure prediction [14]. Using the same cut-off value, the two metrics used for RMSD (summarized in Table 2) indicate that 2 compounds are better ligands of VKOR than brodifacoum (CID 54680676) because they require lesser energy for binding. This suggests that these substances will successfully substitute brodifacoum. The binding energy of the other 12 substances is also high, having identical or lower lipophilicity; consequently, they will eliminate faster, possibly lacking a part of the adverse effects.

We used the default docking parameters:

- number of binding modes: 9 ,

- exhaustiveness (thoroughness of search): 8.

Larger values increase the probability of finding the global minimum, but they also extend the computational time. Increasing the exhaustiveness value increases the time linearly and decreases the probability of not finding the minimum exponentially. Apart from exhaustiveness influenced by users, Vina has an internal heuristic algorithm to extend the search in accordance with an increasing number of atoms and rotatable bonds [15].

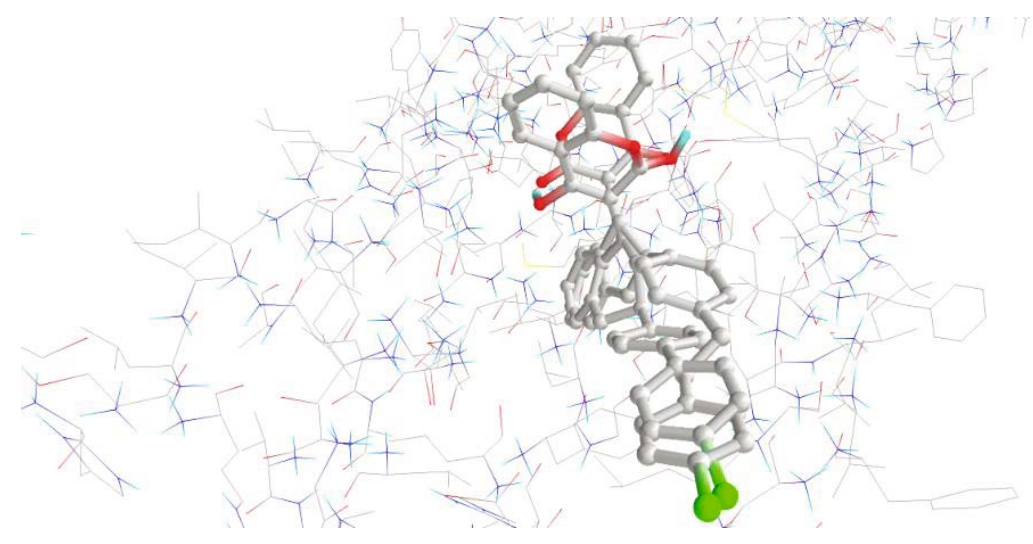

Figure 1. Molecular docking of brodifacoum (CID 54680676) and the ligand CID 54702968 in protein target (Mayavi). 


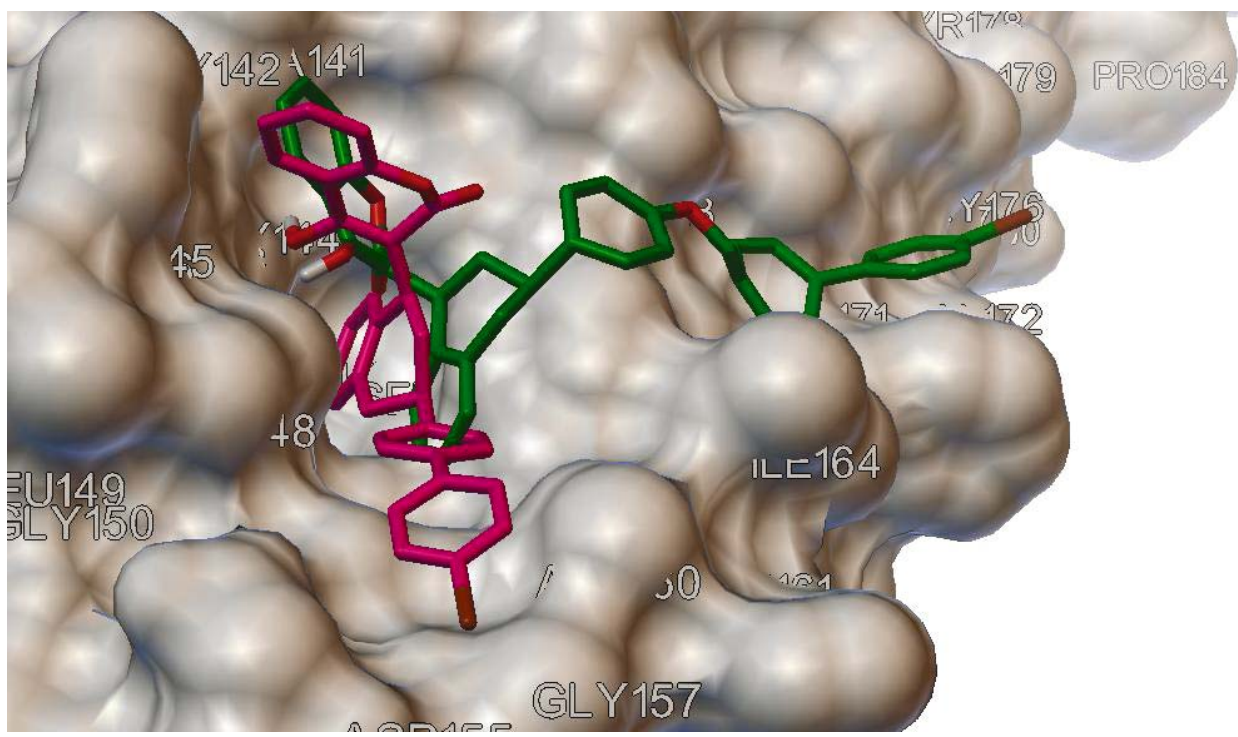

Figure 2. Ligand CID 54721414 and brodifacoum (CID 54680676) on the binding site of VKOR (Autodock).

\section{Conclusion}

Compounds with PubChem ID: 54721414, 54721409, 54721416, 54702967, 54702968, 56999900, 54676115, 54716798, 56610083, 56638536, 56629283, 57166454,57186316 , and 54736729 have good binding affinity to vitamin K epoxide reductase enzyme and they present the correct bound structure prediction; so, they seem to act alike and to be good substitutes for brodifacoum. Further investigations are needed to establish their pharmacodynamic properties and toxicity.

\section{References}

[1] American Bird Conservancy.

http://www.abcbirds.org/abcprograms/policy/toxins/Profiles/brodifacoum.html. Retrieved: 9 April 2015.

[2] http://lpi.oregonstate.edu/mic/vitamins/vitamin-K. Retrieved: 19 April 2015.

[3] U.S. National Library of Medicine, TOXNET®: Toxicology Data Network. http://toxnet.nlm. nih.gov/cgi-bin/sis/search/a?dbs+hsdb:@term+@DOCNO+3916. Retrieved: 9 April 2015.

[4] Morris, G. M., Huey, R., Lindstrom, W., Sanner, M. F., Belew, R. K., Goodsell, D. S., Olson, A. J. (2009), Autodock4 and AutoDockTools4: automated docking with selective receptor flexibility. Journal of Computational Chemistry 16, 2785-2791. 
[5] Trott, O., Olson, A. J. (2010), AutoDock Vina: improving the speed and accuracy of docking with a new scoring function, efficient optimization and multithreading. Journal of Computational Chemistry 31, 455-461.

[6] O’Boyle Noel, M., Banck, M., James Craig, A., Morley, C., Vandermeersch, T., Hutchison Geoffrey, R. (2011), Open Babel: An open chemical toolbox. J. Cheminf. 3, 33-47.

[7] National Center for Biotechnology Information. PubChem Compound Database; CID=54680676, http://pubchem.ncbi.nlm.nih.gov/compound/54680676 (accessed: Dec. 27, 2013 and Apr. 12, 2015).

[8] Sanner, M. F. (1999), Python: A programming language for software integration and development. J. Mol. Graphics Mod. 17, 57-61.

[9] Sanner, M. F., Spehner, J.-C., Olson, A. J. (1996), Reduced surface: an efficient way to compute molecular surfaces, Biopolymers 38(3), 305-320.

[10] Bajaj, C., Park, S., Thane, A. (2002), A parallel multi-PC volume rendering system. ICES and CS Technical Report, University of Texas. http://www.cs.utexas.edu/ bajaj/cvc/software/ docsTRLIB/PMVR.pdf.

[11] Bajaj, C., Pascucci, V., Schikore, D. (1996), Fast isocontouring for improved interactivity. In: Proceedings of ACM Siggraph/IEEE Symposium on Volume Visualization, ACM Press, San Francisco, CA, 39-46.

[12] Sanner, M. F., Stoffler, D., and Olson, A. J. (2002), ViPEr a visual programming environment for Python. In: $10^{\text {th }}$ International Python Conference, Virginia. http://www.scripps.edu/sanner/ $\mathrm{html} /$ papers/IPC02.pdf.

[13] Li, W., Schulman, S., Dutton, R. J., Boyd, D., Beckwith, J., Rapoport, T. A. (2010), Structure of a bacterial homologue of vitamin $\mathrm{K}$ epoxide reductase. Nature 463, 507-512. $\mathrm{http} / / / \mathrm{www} . \mathrm{rcsb}$. org $/ \mathrm{pdb} /$ explore/explore.do?structureId=3kp9.

[14] Bursulaya, B. D., Totrov, M., Abagyan, R., Brooks, C. L. (2003), Comparative study of several algorithms for flexible ligand docking., J. Comput. Aided Mol. Des. 17(11), 755-763.

[15] Wolf, L. K. (2009), New software and websites for the chemical enterprise. Chemical \& Engineering News 87, 31. 